\title{
Rice Physiology, Products, and Critical Steps Associated with Postharvest Operations in Southern Florida ${ }^{1}$
}

\author{
Jehangir H. Bhadha, Sangeeta Mukhopadhyay, Charlene Andrews, and Matthew \\ VanWeelden ${ }^{2}$
}

\section{Introduction}

Nearly 25,000 acres of rice (Oryza sativa L.) were planted in the Everglades Agricultural Area (EAA) of south Florida in 2018. Over the past decade, rice acreage in the EAA has been steadily increasing, and has almost doubled from 2008 to 2018 (Bhadha et al. 2018). As production increases, it is important to highlight useful aspects of postharvest processing and critical steps associated with postharvest rice operations in order to close information gaps regarding rice production and postharvest processing. This document pertains to the UF/IFAS Extension programs related to rice production in the EAA and focuses on the steps that comprise postharvest processing of rice (drying, tempering, milling, and storage). Since rice is primarily consumed as an intact kernel, maintaining kernel integrity throughout the steps of postharvest processing is essential. This document aims to highlight the physiology of the rice kernel and define some of the common terms used in the rice industry, elaborate on the steps in postharvest processing, and provide a brief overview of rice products and their market potential.

\section{Physiology of a Rice Grain}

Rice is a semiaquatic, annual grass plant that is cultivated in more than 100 countries on every continent $\left(53^{\circ} \mathrm{N}\right.$ to $40^{\circ} \mathrm{S}$, from sea level to approximately $9,850 \mathrm{ft}$ above sea level) except Antarctica, but with vastly different production practices (Juliano 1972). In terms of human consumption, rice is the single most important food crop in the world, meeting $21 \%$ of the caloric needs of the world and $76 \%$ of those for Southeast Asia (Fitzgerald et al. 2009).

Rice is harvested as a covered kernel in which the singleseeded fruit (caryopsis) is enclosed in a tough, protective, siliceous bran (hull); this covered kernel is commonly referred to as "rough rice" or "paddy." Figure 1 shows a longitudinal section of a rice kernel. The bran is composed of two modified leaves, the palea and the lemma, that overlap and interlock with each other with the help of two hook-like structures. This interlocking arrangement has been related to the rice kernel's resistance to both insect infestation (Juliano 1981) and fungal damage (Ilag and Juliano 1982). Inside the bran are three distinct layers of cells that constitute the caryopsis coat: the pericarp, the seed coat, and the nucellus. Pigmented rice varieties such as red, purple, or black rice derive their color from the pigments (anthocyanins) located in the pericarp and/or in the seed coat. The embryo (germ) is small and is located on the ventral side of the kernel. The aleurone layer surrounds the rice kernel and the outer side of the embryo; this layer holds almost all of the protein and lipid content of the rice kernel. The caryopsis coat and the aleurone layer together are commonly referred to as "bran." The sub-aleurone layer

1. This document is SS-AGR-438, one of a series of the Agronomy Department, UF/IFAS Extension. Original publication date September 2019. Visit the EDIS website at https://edis.ifas.ufl.edu for the currently supported version of this publication.

2. Jehangir H. Bhadha, assistant professor, Department of Soil and Water Sciences, UF/IFAS Everglades Research and Education Center; Sangeeta Mukhopadhyay, contributor, Florida Crystals; Charlene Andrews, contributor, Florida Crystals; and Matthew VanWeelden, Extension agent II, UF/IFAS Extension Palm Beach County; UF/IFAS Extension, Gainesville, FL 32611.

The Institute of Food and Agricultural Sciences (IFAS) is an Equal Opportunity Institution authorized to provide research, educational information and other services

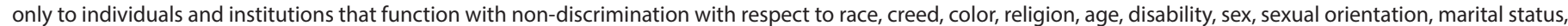

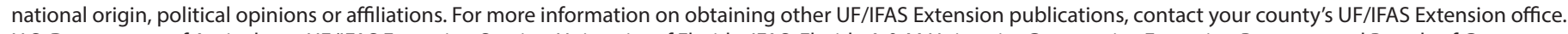
U.S. Department of Agriculture, UF/IFAS Extension Service, University of Florida, IFAS, Florida A \& M University Cooperative Extension Program, and Boards of County Commissioners Cooperating. Nick T. Place, dean for UF/IFAS Extension. 
and the starchy endosperm are underneath the aleurone layer. Rice starch comprises large, polyhedral, compound starch granules that measure 3 to 8 microns in diameter (Tester and Karkalas 2002) and are surrounded by proteinaceous material. The plumule and radicle are joined by a short stem called the hypocotyl. The hypocotyl is bound on the outer side by a single layer of endosperm cells (the sub-aleurone layer) and the fibrous remains of the pericoat. The endosperm also lines the inner edge of the embryo.

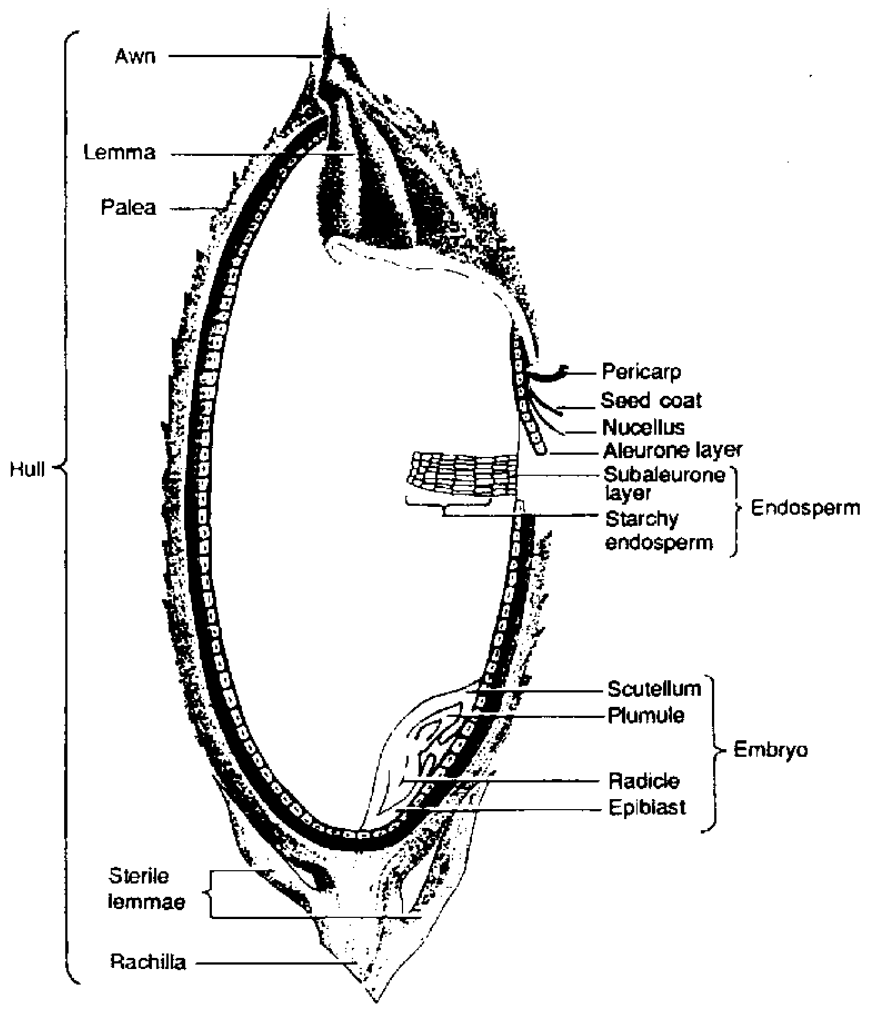

Figure 1. Longitudinal section of a rough rice kernel. Adapted from Juliano and Aldama (1937).

Credits: Sangeeta Mukhopadhyay, Florida Crystals

\section{Postharvest Operation}

In the Southeastern US, rough rice is typically harvested at 14 to $22 \%$ moisture content (wet basis) using combines that mechanically strip the kernels off the rice stalks or panicles. Each combine-load of rough rice kernels is then emptied into a truck. When the truck is full, it brings the harvested rough rice to a rice mill to be dried. Freshly harvested rice needs to be dried to approximately $12.5 \%$ moisture content to minimize respiration rates and mold growth (Dillahunty et al. 2000) and to inhibit fungi and insect growth (Chen et al. 1997).

Typically, rough rice is dried using commercial or on-farm cross-flow drying systems (Figure 2) with elevated air temperatures ranging from $104^{\circ} \mathrm{F}$ to $158^{\circ} \mathrm{F}$ (Schluterman and Siebenmorgen 2004; Billiris et al. 2014; Billiris and Siebenmorgen 2014) to achieve high throughput rates.
Cross-flow dryers are named due to the crosswise direction of movement of rough rice relative to that of the heated air. Rice flows vertically downwards between two perforated metal screens comprising the grain columns (Figure 2) while hot air flows through the columns in a direction perpendicular (or "cross") to that of the rice. Typically, ambient air is first forced into the dryer by an axial or centrifugal fan, then heated by a burner using direct combustion of propane or natural gas, before entering the heated-air plenum of the dryer. The height of the drying section in an on-farm cross-flow dryer is typically $12 \mathrm{ft}$, whereas in commercial systems, this height may be as much as $100 \mathrm{ft}$. Unloading feed-roll augers located at the bottom of the dryer columns combine the columns and meter the rice out of the dryer.

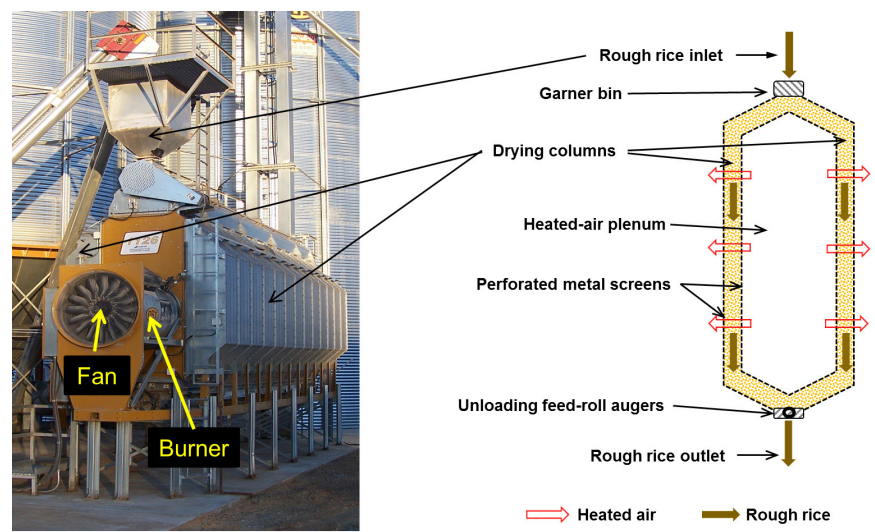

Figure 2. Left: An on-farm cross-flow dryer (Greg Baltz, Pocahontas, Arkansas). Right: A schematic of a cross-flow dryer (Prakash et al. 2017).

Credits: Sangeeta Mukhopadhyay, Florida Crystals

Commercial drying processes for rough rice typically comprise multiple drying passes, with periods of tempering or holding the rice in bins between drying passes. Tempering durations vary widely. They are based on the experience of dryer operators, as well as harvesting and drying logistics. Tempering between drying passes allows intra-kernel material state gradients to subside (Perdon et al. 2000; Cnossen and Siebenmorgen 2000), thereby minimizing fissuring and consequent breakage of rice kernels (Schluterman and Siebenmorgen 2007). Tempering also decreases the total drying duration (Aquerreta et al. 2007) by improving the drying rate in subsequent passes (Nishiyama et al. 2006), thereby increasing overall energy efficiency (Hwang et al. 2009).

Once rough rice is dried to approximately $12.5 \%$ moisture content, it is de-branned (i.e., the bran is removed) to yield brown rice (Figure 3). Rice milling to the white rice-stage consists of a series of abrasive and/or frictional operations that remove the embryo and a specified amount of bran 
from the brown rice kernels, transforming these kernels into white rice or milled rice. During milling, some rice kernels invariably break. As a result, the milled rice fraction contains intact kernels as well as these broken pieces. A series of grading equipment is used to separate the intact kernels from the broken ones. Broken kernels are often ground into flour that is then used in a variety of applications.

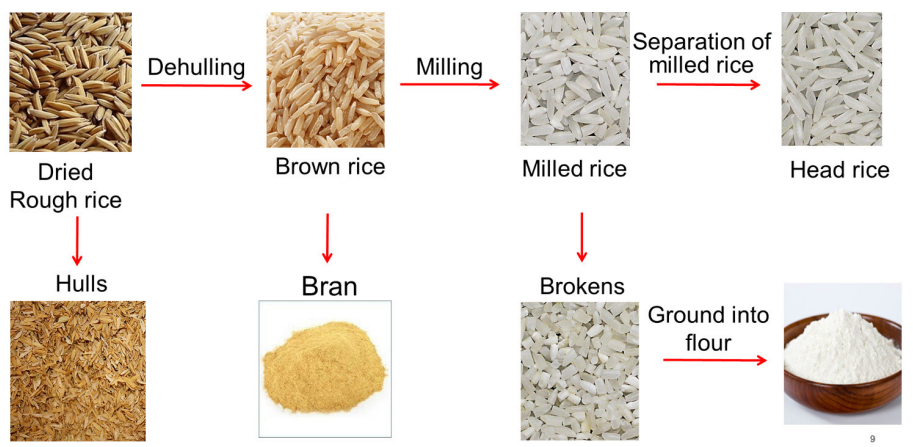

Figure 3. Steps in the postharvest processing of rice.

Credits: Sangeeta Mukhopadhyay, Florida Crystals

Head rice consists of milled kernels that are at least threefourths of the original kernel length (USDA 2009); these are often known as whole kernels or "fancy" in the rice industry (Figure 4). Rice milling yield refers to either or both the milled rice yield (MRY) and the head rice yield (HRY), defined as the mass of milled rice and head rice, respectively, and expressed as a percentage of the original dried rough rice mass (USDA 2009). Figure 5 provides a pictorial representation for the calculation of MRY and HRY. A typical milling yield is expressed as a ratio of HRY to MRY. For example, the milling yield " $58 / 70$ " represents an HRY of 58 and an MRY of 70 . The difference between the MRY and the HRY quantifies the amount of brokens, which are the broken rice kernels (i.e., $70-58=12 \%$ brokens).

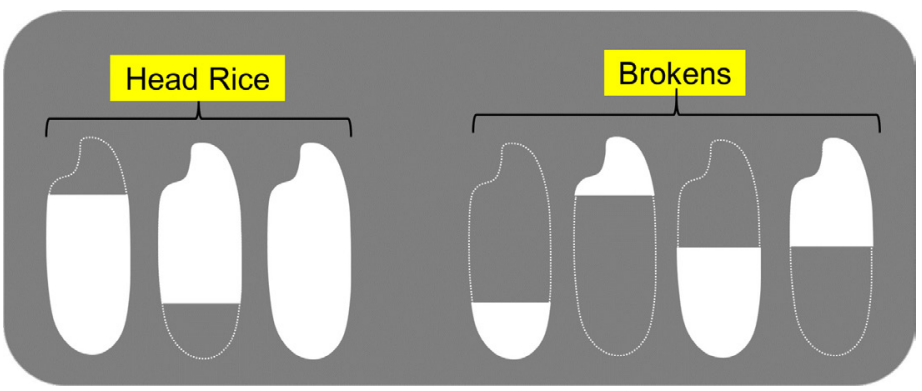

Figure 4. Schematic showing head rice (kernels that are at least threefourths of an original kernel length) and broken rice kernels (also called "brokens").

Credits: Terry J. Siebenmorgen and Sangeeta Mukhopadhyay

It is important to understand the steps of rice processing in terms of a mass balance. A $100-\mathrm{lb}$ lot of rough rice yields 80 $\mathrm{lb}$ of brown rice, since brans constitute $20 \%$ of the mass of rough rice. Depending on the extent of milling, the amount of milled rice obtained from approximately $80 \mathrm{lb}$ of brown rice differs considerably. However, as a rule of thumb, about $10 \%$ is lost in the bran stream, including the embryo and the bran. Thus, the processes of de-branning and milling $100 \mathrm{lb}$ of rough rice typically yield $70 \mathrm{lb}$ of milled rice. Due to a large number of factors, which include cultivar differences, growing location, growing conditions, drying and tempering operations, storage conditions, milling operations, and degree of milling, approximately 45 to 60 $\mathrm{lb}$ survive the milling process and are separated from the milled rice mass as head rice while the remaining 10 to 25 lb become "brokens."

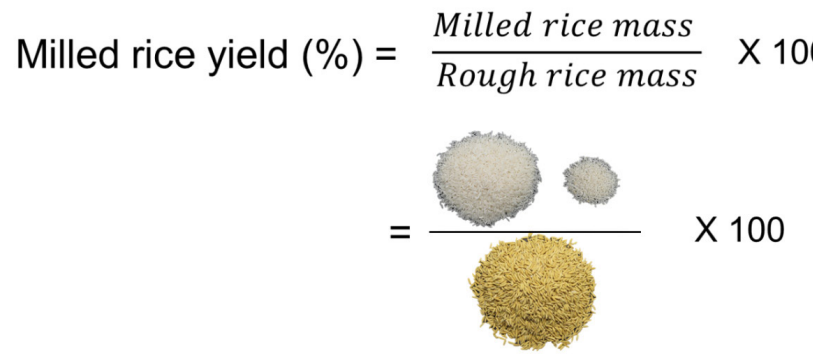

(b) Head rice yield $(\%)=\frac{\text { Head rice mass }}{\text { Rough rice mass }} \times 100$

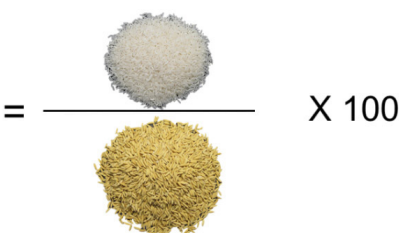

Figure 5. Pictorial representation of the calculation of (a) milled rice yield and (b) head rice yield.

Credits: Sangeeta Mukhopadhyay, Florida Crystals

Current postharvest research efforts are geared towards maximizing HRY while maintaining and improving rice quality attributes, including physiochemical and functional characteristics of rice and rice starch.

\section{Rice, Rice Products, and Their Growing Market Potential}

Rice is unique compared to other cereal grains since it is mostly consumed as table rice, which consists of milled, intact kernels; thus, the importance of maintaining the physical integrity of rice kernels cannot be emphasized enough. In most markets, broken kernels are valued at only 50 to $60 \%$ compared to head rice. Because of the economic importance of head rice relative to broken kernels, the broad objective in rice postharvest processing and management operations, which include drying, tempering, storage, and milling, is to maximize HRY. 
Although broken kernels of rice have been typically underutilized in the rice industry, the demand for rice brokens has increased considerably in recent years. Most of this demand has been due to the increasing number of people diagnosed with Celiac disease, an autoimmune genetic disorder of the small intestine (Hartmann et al. 2006; Woodward 2007), wherein the only treatment is strict adherence to a gluten-free diet. Rice is naturally gluten-free as well as hypoallergenic and is therefore ideal for inclusion in gluten-free diets and formulations. Additionally, brokens are ground into flour. Rice flour is used in most baby foods, rice noodles, pasta, cakes, breads, and several fermented rice products. Rice flour and rice starch are also used in the manufacture of biodegradable and edible films and edible cutlery.

Brokens are extensively used in the US pet food industry, and the recent growth in this industry serves as a boost for their sale. Both brokens and head rice are used for brewing applications. Other co-products of rice processing also have a variety of applications. Brans are used as cattle feed, poultry litter, soil amendment for potting plants, bedding material for plants, tinder to generate heat for parboiling of rice, and medium to clean up major oil spills. Oil is extracted from rice bran to produce rice bran oil, and bran is also mixed with other commodities for animal feed.

\section{References}

Aquerreta, J., A. Iguaz, C. Arroqui, and P. Virseda. 2007. "Effect of high temperature intermittent drying and tempering on rough rice quality." Journal of Food Engineering 80: 611-618.

Bhadha, J. H., R. Khatiwada, S. Galindo, N. Xu, and J. Capasso. 2018. "Evidence of soil health benefits of flooded rice compared to fallow practice." Sustainable Agriculture Research. doi:10.5539/sar.v7n4p31

Billiris, M. A. and T. J. Siebenmorgen. 2014. "Energy use and efficiency of rice-drying systems. II. Commercial, cross-flow dryer measurements." Applied Engineering in Agriculture 30: 217-226.

Billiris, M. A., T. J. Siebenmorgen, and G. L. Baltz. 2014. "Energy use and efficiency of rice-drying systems. I. Onfarm cross-flow dryer measurements." Applied Engineering in Agriculture 30: 205-215.

Chen, H., T. J. Siebenmorgen, and B. P. Marks. 1997.

"Relating drying rate constant to head rice yield reduction of long-grain rice." Transactions of the ASAE 40: 1133-1139.
Cnossen, A. and T. J. Siebenmorgen. 2000. “The glass transition temperature concept in rice drying and tempering: Effect on milling quality." Transactions of the ASAE 43: $1661-1668$.

Dillahunty, A. L., T. J. Siebenmorgen, R. W. Buescher, D. E. Smith, and A. Mauromoustakos. 2000. "Effect of moisture content and temperature on respiration rate of rice." Cereal Chemistry 77: 541-543.

Fitzgerald, M. A., S. R. McCouch, and R. D. Hall. 2009. "Not just a grain of rice: The quest for quality." Trends in Plant Science 14: 133-139.

Hartmann, G., P. Koehler, and H. Wieser. 2006. "Rapid degradation of gliadin peptides toxic for Celiac disease patients by proteases from germinating cereals." Journal of Cereal Science 44: 368-371.

Hwang, S. S., Y. C. Cheng, C. Chang, H. S. Lur, and T. T. Lin. 2009. "Magnetic resonance imaging and analyses of tempering processes." Journal of Cereal Science 50: 36-42.

Ilag, L. L. and B. O. Juliano. 1982. "Colonization and aflatoxin formation by Aspergillus spp. on brown rices differing in endosperm properties." Journal of the Science of Food and Agriculture 33: 97-102.

Juliano, B. O. 1981. Rice Grain Properties and Resistance to Storage Insect: A Review. Res. Paper Ser. 56. Los Baños, Laguna, Philippines: International Rice Research Institute.

Juliano, B. O. 1972. "Chapter 1: Production and utilization of rice." In Rice Chemistry and Technology, edited by B. O. Juliano. 1-16. St. Paul, MN: American Association of Cereal Chemists.

Juliano, J. B. and M. J. Aldama. 1937. "Morphology of Oryza sativa Linnaeus.” Philippine Agriculturist 26: 1-27.

Nishiyama, Y., W. Cao, and B. Li. 2006. "Grain intermittent drying characteristics analyzed by a simplified model." Journal of Food Engineering 76: 272-279.

Perdon, A., T. J. Siebenmorgen, and A. Mauromoustakos. 2000. "Glassy state transition and rice drying: Development of a brown rice state diagram." Cereal Chemistry 77: 708-713. 
Prakash, B., S. Mukhopadhyay, and T. J. Siebenmorgen.

2017. "Mathematical modeling of a cross-flow rice dryer."

Transactions of the ASABE 60: 999-1009.

Schluterman, D. A. and T. J. Siebenmorgen. 2007. "Relating

rough rice moisture content reduction and tempering duration to head rice yield reduction." Transactions of the

ASABE 50: 137-142.

Schluterman, G. J. and T. J. Siebenmorgen. 2004. "Air and rice property profiles within a commercial cross-flow dryer." Applied Engineering in Agriculture 20: 487-494.

Tester, R. F. and J. S. Karkalas. 2002. "Polysaccharides. II. Polysaccharides from eukaryotes." In Biopolymers 6, edited by E. J. Vandamme, S. De Baets, and A. Steinbüchel. 381-438. Weinheim: Wiley-VCH.

U.S. Department of Agriculture. 2009. United States

Standards for Rice. Washington, D.C.: Federal Grain Inspection Service. https://www.gipsa.usda.gov/fgis/standards/

ricestandards.pdf

Woodward, J. 2007. “Celiac disease." Medicine 35: 226-230. 